\title{
Food avoidance is associated with reduced dentitions and edentulousness
}

\author{
Qian Zhang ${ }^{1,2}$ (D) $\cdot$ Dominique Niesten $^{1} \cdot$ Ewald M. Bronkhorst ${ }^{2} \cdot$ Dick J. Witter ${ }^{1} \cdot$ Nico H. J. Creugers ${ }^{1}$
}

Received: 24 February 2019 / Accepted: 6 June 2019 /Published online: 14 June 2019

(C) The Author(s) 2019

\begin{abstract}
Objectives To investigate associations between food avoidance and dental status, age, gender, and socio-economic status (SES). Materials and methods The Chinese sample comprised 1463 dentulous ( $\geq 1$ tooth in each jaw) and 124 edentulous (in one or both jaws) participants aged $\geq 40$ yrs. The Vietnamese sample comprised 2820 dentulous and 253 edentulous participants aged $\geq$ 20 yrs. Food avoidance due to chewing difficulties was scored for regionally common 4 soft and 4 hard foods. Dental status was classified according to the multi-level hierarchical dental functional classification system (HDFC) based on the number and location of teeth and posterior occlusal pairs. Associations were analyzed using multivariate logistic regression analyses.

Results For dentulous participants, the chance of avoiding foods was significantly larger with $<10$ teeth in each jaw $(O R=2.26$ (Chinese sample), respectively 1.74 (Vietnamese sample)), incomplete anterior region $(O R=1.78$, respectively 1.84), "impaired" premolar region $(O R=2.22$, respectively 1.71$)$, or "impaired" molar region $(O R=2.46$, respectively 1.84$)$. Edentulous participants had twice the chance of avoiding foods $(O R=2.01$ respectively 2.20). Avoiding foods was significantly associated with higher age. Participants of low SES (Chinese sample, $O R=1.93$ ) and females (Vietnamese sample, $O R=1.27$ ) had a larger chance of avoiding foods.

Conclusions Avoiding foods was significantly associated with reduced dentitions, edentulousness, and higher age; low SES only in the Chinese and being female only in the Vietnamese sample.

Clinical relevance Incomplete anterior regions, "impaired" premolar or molar regions, and especially edentulousness can be considered significant risk indicators for food avoidance.
\end{abstract}

Keywords Food avoidance $\cdot$ Masticatory ability $\cdot$ Reduced dentitions $\cdot$ Edentulousness

Qian Zhang

qian.zhang@radboudumc.nl

Dominique Niesten

Dominique.niesten@radboudumc.nl

Ewald M. Bronkhorst

Ewald.bronkhorst@radboudumc.nl

Dick J. Witter

Dick.witter@radboudumc.nl

Nico H. J. Creugers

Nico.creugers@radboudumc.nl

1 Department of Oral Function and Prosthetic Dentistry, College of Dental Science, Radboud University Nijmegen Medical Center, Philips van Leydenlaan 25, 6525 EX Nijmegen, The Netherlands

2 Department of Preventive and Restorative Dentistry, College of Dental Science, Radboud University Nijmegen Medical Center, Philips van Leydenlaan 25, 6525, EX Nijmegen, The Netherlands

\section{Introduction}

Objectively assessed masticatory performance (chewing efficiency) decreases as the dentition deteriorates. Generally, a clear relationship has been found between dental status and masticatory performance as determined from chewing tests $[1$, 2]. In addition, a number of studies have shown that tooth loss impairs subjective (perceived) masticatory ability: in general, masticatory ability has been found to be associated with the number of teeth $[1,3]$ and with the number of functional tooth units $[4,5]$, thus closely related to the number and distribution of teeth $[1,3-5]$.

Partially dentate people, especially those with fewer than 10 teeth in each jaw and with an impaired premolar region, generally have lower masticatory performance and more chewing problems [5]. People with a complete dental prosthesis (CDP) have a masticatory performance in the order of $25 \%$ of that of people with complete natural dentitions and a substantial 
number of people with CDPs experience seriously impaired masticatory ability $[1,2,6,7]$.

The ability to eat all foods enables people to enjoy daily meals and to eat the widest variety of foods following dietary guidelines, including hard, stringy, and tough foods, to achieve a healthy balanced diet $[8,9]$. However, as a result of impaired masticatory ability, people may develop food preferences, i.e., toward the selection and consumption of more soft and fewer hard or tough foods $[1,10,11]$. Soft (especially refined) foods are associated with the risk for malnutrition, resulting in higher risk for the metabolic syndrome, diabetes mellitus, obesity, loss of body mass, particularly muscle mass, and sarcopenia $[8,9,12-15]$. On the other hand, hard foods such as fiber-containing grains, vegetables, and fruits are recommended to be a substantial part of the daily diet $[9,11]$. For example, whole-grain cereal consumption has been linked to a reduced risk for developing several chronic diseases such as coronary heart disease, obesity, arteriosclerosis, type- 2 diabetes, and some forms of cancer [15].

The cascade of the relationships between dental status, masticatory ability, and nutritional status is not quite clear. In a systematic review, it was reported that the number of functional tooth units and the number of teeth present in elderly were significantly associated with nutritional status; however, remarkably, the meta-analyses in this review showed no statistically significant association between malnutrition and edentulism and use of dental prosthesis [16]. Another recent systematic review based on longitudinal studies stated that at present, there is no strong evidence regarding the effect of tooth loss on diet and nutrition because of inconsistent results amongst the few longitudinal studies identified [17]. Tada and Miura [7] concluded in yet another systematic review that "discrepant findings suggest that masticatory ability explains only part of the variance in food and nutrient intake of the elderly." For example, it was found that differences in nutrition outcomes (malnutrition, being at risk for malnutrition, normal nutritional status) could be explained by the number of functional tooth units, amongst other things, but also by the perception of xerostomia and Geriatric Oral Health Assessment (GOHAI) outcomes [18]. Another example for unclarity is illustrated in a randomized controlled clinical trial: prosthodontic replacement of missing teeth of partially dentate elders did improve nutritional status as assessed by Mini Nutritional Assessment (MNA) outcomes along with improved masticatory performance, but nutritional status as assessed by hematological biomarkers did not improve [19, 20].

Eating behavior, including selection of foods and possible avoidance of certain foods, is far more complex than just chewing behavior and cannot be explained solely by oral physiology as food choices and food consumption are also driven by memory, psychology, and economic factors [21]. Cross-cultural studies also have demonstrated that eating behavior and food selection are related to local and cultural constraints and habits
[22]. In spite of these differences and constraints, it is recognized that chewing behavior is associated with dental and prosthodontic status $[1,2]$. For example, approximately $60 \%$ of people with extreme shortened dental arches (only 0-2 posterior occluding pairs (POPs)) in Tanzania reported that chewing took too long or that they had to swallow food coarsely; another $35 \%$ reported that they could not chew all kind of foods or had to use special or specially prepared food. Both outcomes indicate food selection toward soft(er) foods [23].

In previous studies [24,25], we explored masticatory ability of dentulous people amongst a Vietnamese and a Chinese population respectively. These studies used a validated hierarchical classification system that expresses oral functionality by number and distribution of teeth in different dental regions. Both studies showed that self-reported masticatory ability was strongly associated with dental and prosthodontic conditions, and that the ability to chew foods was inversely associated with older age. In these papers, the chewing ability was considered as a continuum, ranging from "very easy to chew" to "very difficult to chew, avoiding this food." In both samples, low percentages of participants reported avoiding some soft foods because of chewing difficulties; avoiding hard foods was reported more frequently. However, as described above, especially edentulous people experience chewing difficulties, possibly resulting in the avoidance of specific foods. For this reason, edentulous people were included in the present study.

The aim of the present paper is to analyze the relationship between dental status and avoidance of eating certain foods due to impaired masticatory ability in Vietnamese and Chinese dentulous and edentulous samples.

\section{Methods}

\section{Samples}

The sample constructions for both the Vietnamese and the Chinese sample followed a cluster stratified sampling design, aiming at the proportional distribution of participants according to residence (urban or rural), gender, and age categories. In Vietnam, participants were selected from urban and rural areas of three provinces in Southern Vietnam: Can Tho, An Giang, and Ho Chi Minh (HCM). Urban participants were randomly selected from lists of factory employees and administrative lists of citizens obtained from local authorities; rural participants were randomly selected from representative villages using administrative lists of citizens from local authorities. The sample comprised 2820 dentulous ( $\geq 1$ tooth in each jaw) and 253 edentulous (in one or both jaws) participants aged 20 years and over (mean age dentulous participants, $45.0 \pm 14.8 \mathrm{yrs}$; edentulous participants, $68.2 \pm 11.7$ yrs). Participants in the Chinese sample were selected in the same way in urban and rural areas in Qingdao, Shandong Province. This sample 
comprised 1463 dentulous and 124 edentulous subjects, aged 40 years and over (mean age dentulous participants, 54.9 $10.5 \mathrm{yrs}$; edentulous participants, $70.3 \pm 9.3 \mathrm{yrs}$ ). The percentage of female participants in the Vietnamese sample was 52 and in the Chinese sample 48. The sample construction has been described in detail in the previous reports [24, 25]. From all individual participants included in the study, informed consent was obtained. The investigations were carried out in compliance with the Helsinki Declaration and were approved by the Educational Scientific Committee of Can Tho University of Medicine and Pharmacy (decision no. 390/QĐ ĐHYDCT) and by the ethics committee of the Medical School of Qingdao University, Qingdao, China.

\section{Questionnaire and clinical examination}

Participants were asked to complete a self-administered questionnaire that included demographic items (age, gender, and socio-economic status (SES)) and questions on the participant's ability to chew eight regionally common foods. Some participants who were not able to complete the questionnaire by themselves (e.g., because of illiteracy or visual impairment) were helped by an assistant, who read aloud the questions and recorded the answers. The eight foods were listed randomly in the questionnaire and included four foods that were considered soft and four that were considered hard. The foods considered to be soft were cooked rice, steamed bread, crusts (in the Chinese questionnaire: Shaobing (Chinese-style baked roll)), and meat. The foods considered hard were raw vegetables, raw carrots, apples, and nuts. A questionnaire rating perceived chewing difficulties with common foods of various textures and hardness was used (score 1, (very) easy to chew; score 2, minor problems with chewing, got used to it; score 3, minor problems, cannot get used to it; score 4, difficult to chew, not avoiding this food; score 5, very difficult to chew, not avoiding this food; score 6, very difficult to chew, avoiding this food; score 7, not avoiding this food, but never eating it (for instance if they were vegetarian)) [24, 25]. Where previous reports analyzed masticatory ability on the basis of this questionnaire, the present study analyzes food avoidance. This was done dichotomously by rating a marked score 6 as "yes, avoiding this food" versus rating marked scores 1 to 5 and 7 as "no, not avoiding this food."

For assessment of SES (low, middle, high), a modified Kuppuswamy classification was used [26], which integrates, first, the subject's level of education (5 levels: higher education; college; primary school; no formal education, literate; no formal education, illiterate), and, second, occupation (3 levels: white collar $=$ office worker, teacher, doctor, and academic researcher, government officers; service people = salespeople, house worker, and vehicle driver; blue collar = farmer, factory worker, forestry worker, fisher, and (lower) military personnel). The third criterion is household income (4 levels: income covers expenses, no loans needed; income does not cover expenses, no loans needed; income covers expenses, loans needed incidentally; income does not cover expenses, loans needed regularly).

Following the completion of the questionnaire, participants underwent an oral examination. The principal investigators were calibrated against three experienced researchers (interobserver agreements: kappa's $\geq 0.89$ ). For the present study, of all variables recorded, only the presence of teeth (including third molars), tooth type, and number and location of POPs were considered. A tooth root was considered as an absent tooth. Amongst the Vietnamese edentulous participants, approximately one out of three participants presented without $\mathrm{CDP}(\mathrm{s})$ at the clinical examination.

\section{Data analysis}

Participants of both samples were divided into groups of dentulous and edentulous individuals. People were classified as dentulous if they had $\geq 1$ tooth in each jaw; edentulous people were classified as such if they were edentulous in one or in both jaws. First, number and percentage of participants in both samples that reported avoidance of $\geq 1$ of the four soft foods, $\geq 1$ of the four hard foods, and $\geq 1$ of the eight combined soft and hard foods were calculated according to age categories. The age categories of the two samples differed as a result of different study designs [24, 25]. For analyzing the chance of avoiding $\geq$ 1 food of the eight selected foods, multivariate logistic regression analyses were performed. The variable "avoiding $\geq 1$ food" was the dependent variable whilst "dental status," "age group," "gender," and "SES" were the independent variables. Dentulous participants were classified on the basis of the hierarchical dental functional classification system (HDFC) [24, 25], a dichotomized five-level hierarchical model in which the criteria applied to the levels are based on dental conditions that reflect functionality (Table 1). This classification system was based on the results of a systematic review [27]. In the present study, the classification was based on the presence of natural teeth plus teeth replaced, and on the presence of natural POPs plus POPs replaced, either with fixed or with removable dental prostheses. For edentulous participants, separate logistic regression analyses were performed.

To express the performance of the logistic regression models, the area under the curve (AUC) statistic was used. An AUC of 0.5 indicates the total absence of model fit, an AUC of 1 indicates perfect model fit.

\section{Results}

Of the Chinese dentulous participants, approximately $30 \%$ had low SES, 30\% had middle SES, and 40\% had high SES. In the Vietnamese sample, the distribution was different: 
Table 1 Levels and criteria for dichotomization in the multi-level hierarchical dental functional classification system (HDFC)

\begin{tabular}{|c|c|c|c|}
\hline \multirow[t]{2}{*}{ Level } & \multicolumn{2}{|l|}{ Meeting criterion } & \multirow[t]{2}{*}{ Dichotomy } \\
\hline & Yes & No & \\
\hline Dentition & $\geq 1$ tooth present in each jaw & Edentulous jaw(s) & $\geq 1$ tooth vs. no teeth in each jaw \\
\hline Jaw & $\geq 10$ teeth in both maxilla and mandible & $<10$ teeth in maxilla or mandible & $\begin{array}{l}\geq 10 \text { teeth vs. }<10 \text { teeth in each } \\
\text { jaw }\end{array}$ \\
\hline $\begin{array}{l}\text { Anterior } \\
\text { region }\end{array}$ & All 12 anterior teeth present & $<12$ anterior teeth present & Complete vs. incomplete \\
\hline $\begin{array}{l}\text { Premolar } \\
\text { region }\end{array}$ & 3 or 4 occluding pairs of premolars & $\leq 2$ occluding pairs of premolars & "sufficient" vs. "impaired" \\
\hline Molar region & $\begin{array}{l}\geq 1 \text { occluding pairs of molars at both left and right } \\
\text { side }\end{array}$ & $\begin{array}{l}\text { No occluding pairs of molars at left or right } \\
\text { side }\end{array}$ & “sufficient” vs. "impaired" \\
\hline
\end{tabular}

approximately $60 \%$ of participants had middle SES whilst $20 \%$ had low and $20 \%$ had high SES. Amongst edentulous participants, in China, approximately two-thirds had low SES and in Vietnam approximately one-third. In both edentulous samples, approximately $15 \%$ had high SES.

Table 2 shows the distribution of dentulous and edentulous participants for the Chinese and the Vietnamese sample as divided into age categories. In the Chinese sample, the percentage of dentulous participants that avoided $\geq 1$ of the four soft foods because of "chewing very difficult" ranged from 2.0 (youngest age group 40-49 yrs) to 11.9 (oldest age group $\geq 70 \mathrm{yrs}$ ). With regard to "avoiding $\geq 1$ of the four hard foods," these percentages ranged from 7.0 to 35.6. The percentage of people "avoiding $\geq 1$ of all eight foods" ranged from 7.5 (youngest) to 37.5 (oldest age group). The percentage of edentulous people (apart from the group of 2 subjects aged 40-49 yrs) that avoided $\geq 1$ of all foods ranged from 56.5 (oldest age group) to 58.8 (age group 50-59 yrs).

Table 2 Percentage (number) of participants in the Chinese and Vietnamese sample that reported avoiding eating one or more of the four soft foods, one or more of the four hard foods, and one or more of the
In the Vietnamese sample, the percentages of dentulous participants that avoided $\geq 1$ of the soft foods ranged from 1.0 (youngest age group; 20-35 yrs) to 7.8 (oldest age group; > $65 \mathrm{yrs}$ ). For "avoiding $\geq 1$ hard foods," these percentages ranged from 7.1 (youngest) to 35.3 (oldest). In the Chinese sample, these percentages were slightly higher: 2.0 (youngest age group; 40-49 yrs) and 11.9 (oldest age group; $\geq 70 \mathrm{yrs)} \mathrm{of}$ participants avoided $\geq 1$ soft foods; 7.0 (youngest) and 35.6 (oldest) of participants avoided $\geq 1$ hard foods. Overall (Table 2, column "total"), approximately 3\% (Vietnam) and $5 \%$ (China) of dentulous participants avoided $\geq 1$ of the soft foods; in both samples, approximately $15 \%$ avoided $\geq 1$ of the hard foods. Of all edentulous participants, on average approximately $15 \%$ avoided $\geq 1$ of the soft foods, and roughly half of the participants avoided $\geq 1$ of the hard foods.

The multivariate regression models (Tables 3 and 4) showed that dentulous subjects had a significantly larger chance of avoiding $\geq 1$ foods when having a reduced dentition: $<10$ teeth

eight foods combined, because they found it very difficult to chew, according to age group, and being dentate ( $\geq 1$ tooth in each jaw) or being edentulous in one or both jaws

China

\begin{tabular}{|c|c|c|c|c|c|c|c|c|c|c|}
\hline \multirow[t]{2}{*}{ Age categories } & \multicolumn{2}{|l|}{$40-49$} & \multicolumn{2}{|l|}{$50-59$} & \multicolumn{2}{|l|}{$60-69$} & \multicolumn{2}{|l|}{$\geq 70$} & \multicolumn{2}{|l|}{ Total } \\
\hline & $\begin{array}{l}\text { Dentate } \\
(n=545)\end{array}$ & $\begin{array}{l}\text { Edentulous } \\
(n=2)\end{array}$ & $\begin{array}{l}\text { Dentate } \\
(n=436)\end{array}$ & $\begin{array}{l}\text { Edentulous } \\
(n=17)\end{array}$ & $\begin{array}{l}\text { Dentate } \\
(n=322)\end{array}$ & $\begin{array}{l}\text { Edentulous } \\
(n=36)\end{array}$ & $\begin{array}{l}\text { Dentate } \\
(n=160)\end{array}$ & $\begin{array}{l}\text { Edentulous } \\
(n=69)\end{array}$ & $\begin{array}{l}\text { Dentate } \\
(n=1463)\end{array}$ & $\begin{array}{l}\text { Edentulous } \\
(n=124)\end{array}$ \\
\hline Soft foods & $2.0(11)$ & $0.0(0)$ & $5.3(23)$ & $17.6(3)$ & $8.1(26)$ & $19.4(7)$ & $11.9(19)$ & $21.7(15)$ & $5.4(79)$ & $20.2(25)$ \\
\hline Hard foods & $7.0(38)$ & $0.0(0)$ & $15.6(68)$ & $52.9(9)$ & $22.4(72)$ & $36.1(13)$ & $35.6(57)$ & $55.1(38)$ & $16.1(235)$ & $48.4(60)$ \\
\hline All foods & $7.5(41)$ & $0.0(0)$ & $16.3(71)$ & $58.8(10)$ & $24.2(78)$ & $44.4(16)$ & $37.5(60)$ & $56.5(39)$ & $17.1(250)$ & $52.4(65)$ \\
\hline \multicolumn{11}{|l|}{ Vietnam } \\
\hline \multirow[t]{2}{*}{ Age categories } & $20-35$ & & $36-55$ & & $56-65$ & & $>65$ & & & \\
\hline & $\begin{array}{l}\text { Dentate } \\
(n=890)\end{array}$ & $\begin{array}{l}\text { Edentulous } \\
(n=2)\end{array}$ & $\begin{array}{l}\text { Dentate } \\
(n=1280)\end{array}$ & $\begin{array}{l}\text { Edentulous } \\
(n=43)\end{array}$ & $\begin{array}{l}\text { Dentate } \\
(n=356)\end{array}$ & $\begin{array}{l}\text { Edentulous } \\
(n=48)\end{array}$ & $\begin{array}{l}\text { Dentate } \\
(n=294)\end{array}$ & $\begin{array}{l}\text { Edentulous } \\
(n=160)\end{array}$ & $\begin{array}{l}\text { Dentate } \\
(n=2820)\end{array}$ & $\begin{array}{l}\text { Edentulous } \\
(n=253)\end{array}$ \\
\hline Soft foods & $1.0(9)$ & $0.0(0)$ & $2.8(36)$ & $7.0(3)$ & $3.4(12)$ & $6.3(3)$ & $7.8(23)$ & $14.4(23)$ & $2.8(80)$ & $11.5(29)$ \\
\hline Hard foods & $7.1(63)^{\mathrm{a}}$ & $50.0(1)$ & $13.0(166)^{b}$ & $34.9(15)$ & $19.5(69)^{\mathrm{c}}$ & $43.5(20)^{\mathrm{d}}$ & $35.3(102)^{\mathrm{e}}$ & $52.3(79)^{\mathrm{f}}$ & $14.2(400)^{\mathrm{g}}$ & $47.5(115)^{\mathrm{h}}$ \\
\hline All foods & $7.8(69)$ & $50.0(1)$ & $13.4(172)$ & $34.9(15)$ & $19.9(71)$ & $43.8(21)$ & 36.7 (108) & $49.4(79)$ & $14.9(420)$ & $45.8(116)$ \\
\hline
\end{tabular}

Incomplete data: ${ }^{\mathrm{a}} n=1 ;{ }^{\mathrm{b}} n=3 ;{ }^{\mathrm{c}} n=3 ;{ }^{\mathrm{d}} n=2 ;{ }^{\mathrm{e}} n=5 ;{ }^{\mathrm{f}} n=9 ;{ }^{\mathrm{g}} n=12 ;{ }^{\mathrm{h}} n=11$ 
Table 3 Odds Ratios, $p$ values, and 95\% CI for avoiding one or more of the eight foods due to chewing difficulties according to dental condition for the Chinese participants having $\geq 1$ tooth in each jaw $(n=1463)$ in a multivariate logistic regression model with age group, gender, and SES as background variables

\begin{tabular}{|c|c|c|c|c|}
\hline & & OR & $p$ value & $95 \% \mathrm{CI}$ \\
\hline$<10$ teeth in & & 2.26 & 0.014 & $1.18 \ldots 4.31$ \\
\hline Anterior regi & mplete & 1.78 & 0.003 & $1.21 \ldots 2.62$ \\
\hline Premolar reg & apaired" & 2.22 & 0.001 & $1.37 \ldots 3.58$ \\
\hline Molar region & ired" & 2.46 & $<0.001$ & $1.65 \ldots 3.66$ \\
\hline Age group ${ }^{a}$ & $50-59$ & 1.97 & 0.002 & $1.27 \ldots 3.04$ \\
\hline & $60-69$ & 2.83 & $<0.001$ & $1.80 \ldots 4.46$ \\
\hline & $\geq 70$ & 3.04 & $<0.001$ & $1.78 \ldots 5.18$ \\
\hline Gender $^{\mathrm{b}}$ & & 0.84 & 0.272 & $0.60 \ldots 1.15$ \\
\hline SES $^{\mathrm{c}}$ & Low & 1.72 & 0.005 & $1.18 \ldots 2.52$ \\
\hline & High & 0.51 & 0.002 & $0.33 \ldots 0.78$ \\
\hline Constant & & 1.65 & 0.195 & \\
\hline $\mathrm{AUC}=0.813$ & & & & \\
\hline
\end{tabular}

Reference: ${ }^{\mathrm{a}}$ age group $20-35 ;{ }^{\mathrm{b}}$ male; ${ }^{\mathrm{c}} \mathrm{SES}$ middle. $A U C$, area under the curve

in each jaw (odds ratio $(O R)=2.26$ (Chinese sample; Table 3) and $O R=1.74$ (Vietnamese sample; Table 4)); incomplete anterior region $(O R=1.78$ respectively $O R=1.84)$; "impaired" premolar region $(O R=2.22$ respectively $O R=1.71)$; or "impaired" molar region $(O R=2.46$ respectively $O R=1.84)$. Apart from dental status, older age group and low SES constituted a significantly higher risk for avoiding foods in Chinese participants: $O R=3.04$ for participants $\geq 70$ yrs and $O R=1.72$ for low SES, whereas high SES had a smaller chance $(O R=$

Table 4 Odds Ratios, $p$ values, and 95\% CI for avoiding one or more of the eight foods due to chewing difficulties according to dental condition for the Vietnamese participants having $\geq 1$ tooth in each jaw $(n=2805)$ in a multivariate logistic regression model with age group, gender, and SES as background variables

\begin{tabular}{|c|c|c|c|c|}
\hline & & OR & $p$ value & $95 \% \mathrm{CI}$ \\
\hline \multicolumn{2}{|c|}{$<10$ teeth in each jaw } & 1.74 & 0.006 & $1.17 \ldots 2.57$ \\
\hline \multicolumn{2}{|c|}{ Anterior region incomplete } & 1.84 & $<0.001$ & $1.38 \ldots 2.46$ \\
\hline \multicolumn{2}{|c|}{ Premolar region "impaired" } & 1.71 & 0.002 & $1.22 \ldots 2.39$ \\
\hline \multicolumn{2}{|c|}{ Molar region "impaired" } & 1.84 & $<0.001$ & $1.35 \ldots 2.49$ \\
\hline \multirow[t]{3}{*}{ Age group ${ }^{\mathrm{a}}$} & $36-55$ & 0.97 & 0.834 & $0.70 \ldots 1.34$ \\
\hline & $56-65$ & 1.00 & 0.991 & $0.66 \ldots 1.51$ \\
\hline & $>65$ & 1.71 & 0.012 & $1.13 \ldots 2.60$ \\
\hline \multicolumn{2}{|l|}{ Gender $^{\mathrm{b}}$} & 1.39 & 0.005 & $1.10 \ldots 1.74$ \\
\hline \multirow[t]{2}{*}{ SES $^{\mathrm{c}}$} & Low & 1.13 & 0.365 & $0.86 \ldots 1.49$ \\
\hline & High & 0.77 & 0.105 & $0.56 \ldots 1.06$ \\
\hline \multicolumn{2}{|l|}{ Constant } & 0.41 & 0.001 & \\
\hline \multicolumn{5}{|l|}{$\mathrm{AUC}=0.766$} \\
\hline
\end{tabular}

Reference: ${ }^{\mathrm{a}}$ age group $20-35 ;{ }^{\mathrm{b}}$ male; ${ }^{\mathrm{c}} \mathrm{SES}$ middle. $A U C$, area under the curve
0.51). Gender had no significant association with avoiding foods in the Chinese sample (Table 3). In contrast, in the Vietnamese sample, age group had no significant relationship with avoiding foods, except for the age group $>65$ yrs $(O R=$ 1.71), whereas female participants showed a higher risk for avoiding foods $(O R=1.39)$. SES had no significant association with avoiding foods due to chewing difficulties (Table 4).

Edentulous participants-compared to dentulous participants - had twice the chance (Chinese sample: $O R=$ 2.01, Vietnamese sample: $O R=2.20$ ) of avoiding $\geq 1$ food because of chewing difficulties (Tables 5 and 6). In both samples, higher age groups had a significantly higher chance of avoiding foods (ORs 5.93 and 6.63 for the oldest age groups). Again, in the Chinese sample, edentulous participants with low SES had a significantly larger chance of food avoidance $(O R=1.93)$ (Table 5). In the Vietnamese sample, females had a larger chance of food avoidance than males $(O R=1.27)$ (Table 6).

$A U C$ s of the regression models for dentulous participants were 0.813 (Chinese sample; Table 3), respectively 0.766 (Vietnamese sample; Table 4), indicating fair to good model fit. For edentulous participants, $A U C \mathrm{~s}$ of the models were 0.746 (Table 5) respectively 0.674 (Table 6), indicating a fair model fit for the Chinese sample and poor model fit for the Vietnamese sample.

\section{Discussion}

For the Vietnamese sample, urban participants were randomly selected from lists of factory employees and administrative lists of citizens obtained from local authorities, and rural participants were randomly selected from representative villages using administrative lists of citizens from local authorities in three provinces in the southern part of Vietnam. Therefore, we

Table 5 Odds ratios, $p$ values, and 95\% CI for avoiding one or more of the eight foods due to chewing difficulties for edentulous (in one or both jaws) Chinese participants $(n=124)$ in a multivariate logistic regression model with age group (yrs), gender, and SES as background variables

\begin{tabular}{lllll}
\hline & & OR & $p$ value & $95 \% \mathrm{CI}$ \\
\hline Edentulous $^{\mathrm{a}}$ & & 2.01 & 0.001 & $1.31 \ldots 3.06$ \\
Age group $^{\mathrm{b}}$ & $50-59$ & 2.50 & $<0.001$ & $1.66 \ldots 3.75$ \\
& $60-69$ & 4.02 & $<0.001$ & $2.66 \ldots 6.07$ \\
& $\geq 70$ & 6.63 & $<0.001$ & $4.25 \ldots 10.36$ \\
Gender $^{\mathrm{c}}$ & & 0.82 & 0.146 & $0.62 \ldots 1.07$ \\
SES $^{\mathrm{d}}$ & Low & 1.93 & $<0.001$ & $1.39 \ldots 2.67$ \\
& High & 0.44 & $<0.001$ & $0.30 \ldots 0.65$ \\
Constant & & 0.11 & $<0.001$ &
\end{tabular}

$\mathrm{AUC}=0.746$

Reference: ${ }^{\mathrm{a}}$ dentate $\left(\geq 1\right.$ tooth in each jaw); ${ }^{\mathrm{b}}$ age group $40-49 ;{ }^{\mathrm{c}}$ male;

${ }^{\mathrm{d}}$ SES middle. AUC, area under the curve 
Table 6 Odds ratios, $p$ values, and 95\% CI for avoiding one or more of the eight foods due to chewing difficulties for edentulous (in one or both jaws) Vietnamese participants $(n=253)$ in a multivariate logistic regression model with age group (yrs), gender, and SES as background variables

\begin{tabular}{lllll}
\hline & & OR & $p$ value & $95 \%$ CI \\
\hline Edentulous $^{\mathrm{a}}$ & & 2.20 & $<0.001$ & $1.62 \ldots 2.98$ \\
Age group $^{\mathrm{b}}$ & $36-55$ & 1.86 & $<0.001$ & $1.39 \ldots 2.49$ \\
& $56-65$ & 3.09 & $<0.001$ & $2.19 \ldots 4.35$ \\
& $>65$ & 5.93 & $<0.001$ & $4.25 \ldots 8.28$ \\
Gender $^{\mathrm{c}}$ & & 1.27 & 0.020 & $1.04 \ldots 1.54$ \\
SES $^{\mathrm{d}}$ & Low & 1.20 & 0.126 & $0.95 \ldots 1.52$ \\
& High & 0.77 & 0.068 & $0.59 \ldots 1.02$ \\
Constant & & 0.06 & $<0.001$ & \\
AUC $=0.674$ & & & & \\
\hline
\end{tabular}

Reference: ${ }^{\mathrm{a}}$ dentate $\left(\geq 1\right.$ tooth in each jaw); ${ }^{\mathrm{b}}$ age group $20-35 ;{ }^{\mathrm{c}}$ male; ${ }^{\mathrm{d}}$ SES middle. AUC, area under the curve

consider the Vietnamese sample representative of the southern provinces of that country [24]. The study in China was conducted amongst urban and rural people in the province of Shandong. The Chinese rural sample is considered to reflect the rural population in that province, and the urban sample reflects the population of Qingdao City. In general, people living on the north-east coast of China are relatively prosperous compared to other regions; therefore, this province cannot be considered as representative of China as a whole [25].

Several questionnaires have been developed for evaluating food choice amongst people of different cultures [22]. However, most of these questionnaires aim to study motivational dimensions, such as mood, convenience, price, weight control, food intolerance, and their influence on food preferences. In these motivational studies, the chewing ability has been rarely included as a variable. In a review aiming to evaluate chewing ability measures, questionnaires rating perceived chewing difficulties with foods of various textures and hardness were recognized as a common technique, which uses ranking scores from "very easy" to "very difficult" to chew in relations to prosthodontic treatments [28]. In the present study, we used such a questionnaire to assess food avoidance as an ultimate consequence of chewing difficulties in association with different dental conditions.

The main finding of the present study is that relatively small proportions of the dentulous participants (1.0-11.9\%, depending on the age group) avoided one or more of the four selected soft foods, but larger proportions (7.0-35.6\%) avoided one or more of the selected hard foods. For the highest age groups of dentulous participants, the chance of avoiding hard foods was substantial in both samples: approximately $35 \%$. Of edentulous participants in the highest age groups of both samples, this percentage was slightly over 50 .
At all levels of the hierarchical classification system, avoiding foods was significantly associated with impairment of the dentition, including the incompleteness of the anterior region; the latter was stronger associated with food avoidance as found in the present study than with masticatory ability as previously reported [24, 25]. Of edentulous participants in both samples, the risk for avoiding at least one of the foods was approximately twice as high (ORs 2.01 and 2.20) as for dentulous participants.

Especially avoiding hard foods bears a risk for malnutrition. Montagnese et al. (2015) pointed to "the basic message [in dietary guidelines] to consume adequate amounts of grains, vegetables, and fruits with moderate intake of fats, sugars, meats, caloric beverages, and salt" [9]. The outcomes of the present study in two large Asian samples are in line with findings from a cross-sectional nation-wide British survey amongst people 65 years and older. In that survey, about one in five dentulous free-living people had difficulty eating raw carrots, apples, well-done steak or nuts; for edentulous institutionalized people wearing dentures, over half of them could not easily eat these types of food [11]. In this British survey, however, participants were asked about chewing difficulties, but not explicitly - as in the present study - whether or not they avoided the consumption of foods because of chewing difficulties.

Malnutrition is a serious condition, especially amongst elderly people. In Europe and North America, the prevalence of malnutrition is $1-15 \%$ amongst independently living older individuals and 25-60\% amongst institutionalized elderly patients [29, 30]. To our knowledge, studies investigating the prevalence of malnutrition amongst adults and elderly in China and Vietnam are lacking. However, in a Chinese study on nutrient supplement use, malnutrition was recognized as "double burden," meaning overweight and chronic diseases in urban and rural areas on the one hand, and stunting and underweight amongst poor rural residents on the other hand [31].

Malnutrition is associated with morbidity, mortality, and costs of care. In spite of this, nutritional problems in older adults often remain undetected or unaddressed [29]. It has been reported that, in general, dietary patterns of older adults with greater adherence to diets that emphasized whole fruits and vegetables, whole grains, low-fat dairy, lean meats, legumes, and nuts were inversely associated with mortality [30]. Moreover, especially older people need optimal protein intake to slow down or perhaps prevent loss of body mass, especially muscle mass and muscle strength or eventually sarcopenia, and to slow down the rate of bone loss and bone mass density [8, 9, 32]. In the samples of the present study, raw carrots, raw vegetables, apples, and nuts were avoided in high percentages amongst the older participants. Although we have no direct information about the nutritional status of the participants in the present study, the high percentages of older participants that reported food avoidance indicate that these 
people are at risk for malnutrition, especially when edentulous. In spite of the significant relationships between avoiding certain foods and dental status, edentulousness, age, gender, and SES, it is worth mentioning that these variables explain only part of the variance in the food avoidance ( $A U C \mathrm{~s}$ ranging from 0.674 to 0.813 ). Nevertheless, these AUC outcomes indicate that the included variables in the models are reasonable (one poor, two fair, and one good) predictors for food avoidance. The AUC of the regression model for edentulous Vietnamese participants was lower than that for the Chinese edentulous participants. This might be explained by the circumstance that a substantial proportion (approximately onethird) of the Vietnamese edentulous sample did not present with CDP at the clinical examination. It can be assumed that these participants were not in possession of (functional) $\mathrm{CDP}(\mathrm{s})$ that could be used for eating meals. On the other hand, it is not certain that people presenting with $\mathrm{CDP}(\mathrm{s})$ used their $\mathrm{CDP}(\mathrm{s})$ for eating meals.

As could be expected, individuals with high SES in the Chinese sample showed a lower chance of avoiding foods and those with low SES a higher chance of doing so compared to individuals with middle SES. In the Vietnamese sample, these trends were in the same direction but did not reach a statistically significant level. We can speculate the reasons for this as, for example, that people with higher education realize the importance of eating a variety of foods, including hard foods.

The relationship between gender and food avoidance cannot be explained by the outcomes of this study. Females in the Vietnamese sample - both dentulous and edentulous - had a significantly larger chance of avoiding foods; in contrast, females in the Chinese sample had a smaller chance for avoiding foods, although this was not statistically significant. It might be that the approximately 10-year mean age difference between the Vietnamese and Chinese dentulous people plays a role in this. However, a much smaller age difference (approximately 2 years) was found between the samples of edentulous people, whilst the same phenomenon was observed. Possibly, cultural differences and dietary preferences play a role in gender effects, although this is speculative and needs further investigation.

Identifying at an early stage those who are malnourished and at risk for malnutrition is important for treating them at an early stage and improving patients' overall prognosis [33]. Dentists can play a role in this $[34,35]$. In periodical oral check-up visits, high-risk individuals for malnutrition may be identified on the basis of age, medical history, and anamnesis, but, also on the basis of dental or prosthodontic status. Subsequently, a possible masticatory disability that could lead to the avoidance of foods can be discussed. Simple dietary advice as given by dentists appeared to improve nutrient intake of edentulous elderly people who had received new CDPs; without such advice, an improvement could not be assessed [36, 37]. In selected cases, discussion with informal caregivers and/or referral to medical professionals (e.g., the family doctor or a dietician) is worth considering.

\section{Conclusions}

In these Chinese and Vietnamese samples, having at least 10 teeth in each jaw, complete anterior region, "sufficient" premolar, and "sufficient" molar region were associated with a significantly smaller chance of food avoidance because of chewing difficulties. Edentulousness and higher age were also significantly associated with avoidance of (especially hard) foods. Associations between food avoidance and low SES and being female were less convincing.

Acknowledgments The authors thank Dr. TC Nguyen for collecting the Vietnam data.

Funding The work was supported by the Department of Oral Function and Prosthetic Dentistry, Radboud University Medical Centre, the Netherlands.

\section{Compliance with ethical standards}

Conflict of interest The authors declare that they have no conflict of interest.

Ethical approval All procedures performed in studies involving human participants were in accordance with the ethical standards of the institutional and/or national research committee and with the 1964 Helsinki declaration and its later amendments or comparable ethical standards.

Informed consent Informed consent was obtained from all individual participants included in the study.

Open Access This article is distributed under the terms of the Creative Commons Attribution 4.0 International License (http:// creativecommons.org/licenses/by/4.0/), which permits unrestricted use, distribution, and reproduction in any medium, provided you give appropriate credit to the original author(s) and the source, provide a link to the Creative Commons license, and indicate if changes were made.

\section{References}

1. Van der Bilt A (2011) Assessment of mastication with implications for oral rehabilitation: a review. J Oral Rehabil 38:754-780

2. Fontijn-Tekamp FA, Slagter AP, Van der Bilt A, Van 't Hof MA, Witter DJ, Kalk W, Jansen JA (2000) Biting and chewing in overdentures, full dentures, and natural dentitions. J Dent Res 79: $1519-1524$

3. Naka O, Anastassiadou V, Pissiotis A (2014) Association between functional tooth units and chewing ability in older: a systematic review. Gerodontol 31:166-177

4. Sato N, Ono T, Kon H, Sakurai N, Kohno S, Yoshihara A, Miyazaki $\mathrm{H}$ (2016) Ten-year longitudinal study on the state of dentition and 
subjective masticatory ability in community-dwelling elderly people. J Prosthodont Res 60:177-184

5. Shao Z, Guo X, Zhang Q, Bronkhorst EM, Zou D, Creugers NHJ (2018) Masticatory efficiency in patients with partially dentate dentitions. J Dent 75:41-47

6. Witter DJ, Tekamp FA, Slagter AP, Kreulen CM, Creugers NHJ (2011) Swallowing threshold parameters of subjects with complete dentures and overdentures. Open J Stomatol 1:69-74

7. Tada A, Miura H (2014) Systematic review of the association of mastication with food and nutrient intake in the independent elderly. Arch Gerontol Geriatr 59:497-505

8. Bauer J, Biolo G, Cederholm T, Cesari M, Cruz-Jentoft AJ, Morley JE, Phillips S, Sieber C, Stehle P, Teta D, Visvanathan R, Volpi E, Boirie Y (2013) Evidence-based recommendations for optimal dietary protein intake in older people: a position paper from the PROT-AGE study group. J Am Med Dir Assoc 14:542-559

9. Montagnese C, Santarpia L, Buonifacio M, Nardelli A, Caldara AR, Silvestri E, Contaldo F, Pasanisi F (2015) European foodbased dietary guidelines: a comparison and update. Nutrition 31: 908-915

10. Walls AWG, Steele JC (2004) The relationship between oral health and nutrition in older people. Mech Ageing Dev 125:853-857

11. Sheiham A, Steele JC (2001) Does the condition of the mouth and teeth affect the ability to eat certain foods, nutrient and dietary intake and nutritional status amongst older people? Public Health Nutr 4:797-803

12. Rondanelli M, Perna S, Faliva MA, Peroni G, Infantino V, Pozzi R (2015) Novel insights on intake of meat and prevention of sarcopenia: all reasons for an adequate consumption. Nutr Hosp 32:2136-3143

13. Mesquita de Carvalho C, Dias Mendonça D, Haas Piovesan C, Edler Macagnan F, Pandolfo Feoli AM (2015) Nutritional adequacy in subjects with metabolic syndrome. Nutr Hosp 31:1147-1153

14. Zitvogel L, Pietrocola F, Kroemer G (2017) Nutrition, inflammation and cancer. Nat Immunol 18:843-850

15. Bach Knudsen KE, Nørskov NP, Bolvig AK, Hedemann MS, Lærke HN (2017) Dietary fibers and associated phytochemicals in cereals. Mol Nutr Food Res 61(7). https://doi.org/10.1002/ mnfr.201600518

16. Toniazzo MP, Amorim PS, Muniz FWMG, Weidlich P (2018) Relationship of nutritional status and oral health in elderly: systematic review with meta-analysis. Clin Nutr 37:824-830

17. Gaewkhiew P, Sabbah W, Bernabé E (2017) Does tooth loss affect dietary intake and nutritional status? A systematic review of longitudinal studies. J Dent 67:1-8

18. El Osta N, Hennequin M, Tubert-Jeannin S, Aboud Naaman NB, El Osta L, Geahchan N (2014) The pertinence of oral health indicators in nutritional studies in the elderly. Clin Nutr 33:316-321

19. Guigoz Y (2006) The mini nutritional assessment (MNA) review of the literature - what does it tell us? J Nutr Health Aging 10:466-485

20. Wallace S, Samietz S, Abbas M, McKenna G, Woodside JV, Schimmel M (2018) Impact of prosthodontic rehabilitation on the masticatory performance of partially dentate older patients: can it predict nutritional state? Results from a RCT. J Dent 68:66-71

21. Mioche L, Bourdiol P, Peyron M-A (2004) Influence of age on mastication: effects on eating behavior. Nutr Res Rev 17:43-54

22. Cunha LM, Cabral D, Moura AP, Vaz de Almeioda MD (2018) Application of the food choice questionnaire across cultures: systematic review of cross-cultural and single country studies. Food Qual Prefer 64:21-36
23. Sarita PTN, Witter DJ, Kreulen CM, Van 't Hof MA, Creugers NHJ (2003) Chewing ability of subjects with shortened dental arches. Community Dent Oral Epidemiol 31:328-334

24. Nguyen TC, Witter DJ, Bronkhorst EM, Gerritsen AE, Creugers NHJ (2011) Chewing ability and dental functional status. Int J Prosthodont 24:428-436

25. Zhang Q, Witter DJ, Bronkhorst EM, Creugers NHJ (2013) Chewing ability in an urban and rural population over 40 years in Shandong Province, China. Clin Oral Investig 17:1425-1435

26. Kuppuswami's SES classification. http://www.scribd.Com/doc/ $18658493 /$ kuppuswamys-SES-Classification?autodown= doc,cited. Accessed 9 Sept 2009

27. Gotfredsen K, Walls AW (2007) What dentition assures oral function? Clin Oral Implants Res 18(Suppl. 3):34-45

28. Feine JS, Lund JP (2006) Measuring chewing ability in randomized controlled trials with edentulous populations wearing implant prostheses. J Oral Rehabil 33:301-308

29. Fávaro-Moreira NC, Krausch-Hofmann S, Matthys C, Vereecken C, Vanhauwaert E, Declercq A, Bekkering GE, Duyck J (2016) Risk factors for malnutrition in older adults: a systematic review of the literature based on longitudinal data. Adv Nutr 7:507-522

30. Ford DW, Jensen GL, Hartman TJ, Wray L, Smiciklas-Wright H (2013) Association between dietary quality and mortality in older adults: a review of the epidemiological evidence. J Nutr Gerontol Geriatr 32:85-105

31. Gong W, Liu A, Yao Y, Ma Y, Ding C, Song C, Yuan F, Zhang Y, Feng G, Chen Z, Ding G (2018) Nutrient supplement use among the Chinese population: a cross-sectional study of the 2010-2012 China nutrition and health surveillance. Nutrients 10:1733

32. Paddon-Jones D, Rasmussen BB (2009) Dietary protein recommendations and the prevention of sarcopenia. Curr Opin Clin Nutr Metab Care 12:86-90

33. Riobó Serván P, Sierra Poyatos R, Soldo Rodríguez J, GómezCandela C, Garciá Luna PP, Serra-Majem L (2015) Special considerations for nutritional studies in elderly. Nutr Hosp 31(Suppl. 3): 84-90

34. DiMaria-Ghalili RA, Mirtallo JM, Tobin BW, Hark L, Van Horn L, Palmer CA (2014) Challenges and opportunities for nutrition education and training in the health care professions: intraprofessional and interprofessional call to action. Am J Clin Nutr 99:1184S$1193 \mathrm{~S}$

35. Harris R, Gamboa A, Dailey Y, Ashcroft A (2012) One-to-one dietary interventions undertaken in a dental setting to change dietary behavior (Review). Cochrane Database of Systematic Reviews Issue 3 Art. No CD006540, DOI: https://doi.org/10.1002/ 14651858.CD006540.pub2

36. Bradbury J, Thomason JM, Jepson NJA, Walls AWG, Allen PF, Moynihan PJ (2006) Nutrition counseling increases fruit and vegetable intake in the edentulous. J Dent Res 8:463-468

37. Suzuki H, Kanazawa M, Komagamine Y, Iwaki M, Jo A, Amagai N, Minakuchi S (2018) The effect of new complete denture fabrication and simplified dietary advice on nutrient intake and masticatory function of edentulous elderly: a randomized-controlled trial. Clin Nutr 37:1441-1447

Publisher's note Springer Nature remains neutral with regard to jurisdictional claims in published maps and institutional affiliations. 